\author{
Е.C. Мордас
}

\title{
ЗАВИСТЬ К БЕРЕМЕННОСТИ И ФАНТАЗИИ О БЕРЕМЕННОСТИ У МУЖЧИН
}

\begin{abstract}
Аннотация. В работе представлен обзор некоторых психоаналитических идей, посвященных теме зависти мужчины к женщине (репродуктивным возможностям женщины), мужским фантазиям о беременности. 3. Фрейд отмечал в контексте своей фаллоцентрической теории специфическое проявление зависти (у женщин), а именно зависть к пенису. Анализ зависти к пенису и женского кастрационного комплекса имеет важное значение для психоаналитической терапии женщин. $K$ сожалению, не так много работ посвящено теме зависти мужчины к женскому полу и детородной функции, а также той роли, которую это чувство играет в развитии мужского характера и психопатологии. Несмотря на то, что разочарование мальчика в этом отношении столь же глубоко, как зависть к пенису у девочки. Чувство зависти беременности и деторождению, фантазии о беременности - значимый материал для понимания идентификации мужчины с женской фигурой и формирования мужской половой идентичности. Психоаналитический опыт показал доэдипальный период возникновения чувства зависти. Мальчик хочет быть всемогущим как мать, и иметь способность к деторождению. Это выражение гермафродитического желания и бисексуальности человека. Стадия анального эротизма позволяет мальчику фантазировать о беременности, не имея феминных наклонностей. Идентификация с матерью способствует тому, что мальчик обходит кастрационные переживания, сохраняет связь с матерью (то есть предупреждает разлуку). Посредством фантазий о беременности мальчик выражает желание стать ребенком; фантазия появляется в ситуации, когда необходимо проявить мужественность. Идентификация с матерью позволяет мальчику (мужчине) стать любимым для отца. Фантазии о беременности мужчины поддерживают идентификацию с женской фигурой и возможным источником которых (фантазий) является зависть к матери, способной к деторождению. Провоцирующие внешние обстоятельства (беременность жены, аналитика) приводят к потере психического равновесия мужчины, регрессии. Возникающее новое психическое равновесие зависит от структуры Эго и исходного конфликта и структуры личности. Беременность является одним из решающих периодов развития для мужчин и для женщин.Отдельно стоит отметить недостаточность клинического психоаналитического материала (психотерапевтической практики, в частности), посвященного психоанализу беременности, доступного русскоязычному читателю.
\end{abstract}

Ключевые слова: зависть, беременность, страх кастрации, фантазии, феминность, деторождение, маскулинность, регресс, желание ребенка, идентификация.

Abstract. The paper presents an overview of some psychoanalytic ideas about envy of male to female (reproductive capabilities of women), men's fantasies about pregnancy. Freud noted a specific manifestation of envy (women) penis envy in the context of its fallocentrically theory. Analysis of penis envy and the feminine castration complex is essential for psychoanalytic therapy women. Unfortunately, there are not a lot of works devoted to the theme of envy of men towards the female sex and reproductive functions, as well as the role which feeling plays in the development of men's character and of psychopathology. Despite of the disappointment of the boy in this respect is as deep as the penis envy of the girl. Envy to pregnancy and childbirth, fantasies about pregnancy is a significant contribution to the understanding of identification of a man with a female figure and the formation of male gender identity. Psychoanalytic experience has shown preedipally period of the appearance of feelings of envy. The boy wants to be the Almighty as a mother and to have the ability to have children. This is expression of hermaphroditical desire and bisexuality of man. The stage of anal eroticism allows the boy to fantasize about pregnancy, not having feminine tendencies. Identification with the mother contributes to the fact that the boy bypasses castration feelings and maintains a relationship with the mother (i.e. to prevent separation). Through fantasies about pregnancy boy expresses a desire to become a child; fantasy appears in a situation when it is necessary to show manhood. Identification with the mother allows the boy (man) become a favorite for his father. Men's fantasies about pregnancy support the identification with a female figure and possible source of them (fantasies) is the envy of the mother. Provoking external circumstances (wife's pregnancy, analytics) lead to loss of mental balance and men's regression. Emerging new mental balance depends on the structure 
of the Ego, initial conflict and the structure of personality. Pregnancy is one of the key periods of development for men and women. We should also note the shortage of the clinical psychoanalytic material (psychotherapy practice, in particular), devoted to the psychoanalysis of pregnancy available for Russian readers.

Key words: envy, pregnancy, fear of castration, fantasy, femininity, childbirth, masculinity, a regression, a child's desire, identification.

$\mathrm{H}$ е так много случаев в психоаналитической литературе посвящено зависти беременности у мужчин, хотя идеи о фантазиях беременности у женщин-мужчин встречаются чаще. Природа фантазий о беременности заключается в наличии доэдипальной идентификации с матерью в качестве защиты от переживаний вытесненного гнева и страха кастрации, а также первичное доэдипальное асексуальное желание со стороны ребенка - быть похожим на мать и иметь ребенка, часто в попытке быть ближе к ней. Считается, что это регрессивное явление возникает у мужчины в моменты, когда необходимо проявить маскулинные качества [18]. 3. Фрейд описал фантазии Шребера о превращении в женщину. Он отмечал, что теория клоаки позволяет мальчику иметь фантазии о рождении, не имея женских гениталий и женских наклонностей. Ранк нашел антропологические доказательства того, что фантазии о продолжении рода у детей предшествуют знанию половых различий и поэтому являются прегенитальными. Клинические исследования Брюнсвик ${ }^{1}$ [Brunswick R.M.], Макалплайна [Macalpine I.] и Хантера [Hunter R.A.] подтверждают идею о том, что раннее желание ребенка связано с активностью и всемогуществом, а не развитием по женскому типу. Речь идет о доэдипальном гермафродитическом желании подражать активной, всемогущей, фаллической матери и иметь возможность делать все, что позволено и доступно ей, в том числе иметь детей. Это контрастирует с более поздним бисексуальным эдиповым желанием. Желание мальчика отождествлять себя с активной всемогущей матерью не ставит перед ним проблему подчинения кастрации и превращения в девочку вместо мальчика. Скорее, это дает ему возможность стать девочкой в дополнение к тому, что он уже является мальчиком [17].

Более того, М. Кляйн утверждает, что переживания по поводу невозможности реализовать желание мальчика - родить ребенка, заставляет его чувствовать себя низшим по сравнению матери, и, следовательно, формирует компенсацию, которая выражается в проявлении превосходства над женщиной, что выводит на гордость за то, что мальчик владеет пенисом. Сверхкомпенсация приводит к завышению маскулинности [11].

\footnotetext{
${ }^{1}$ Фаллическая мать - детская фантазия по Р.М. Брюнсвик.
}

В работе «Некоторые психические следствия анатомического различия полов» 3 . Фрейд описал последствия зависти к пенису у девочек: ревность к мужчине, нарциссическое повреждение, чувства неполноценности и ослабление отношений с матерью как объектом любви [6]. Он считал развитие мальчика менее сложным, чем девочки, поскольку мальчик на эдиповой стадии только сменяет объект для идентификации из-за страха кастрации. Девочка же вынуждена не только сменить объект для идентификации, но и область телесного удовольствия (клитор на вагину, что фактически означает инвестицию либидо в вагинальную область $=$ женственность). Р.Дж. Столлер [4], напротив, отметит сложности в развитии половой идентичности мальчика, и эти сложности свяжет с кастрационными переживаниями, не устоявшимся чувством мужественности. Как результат не прожитых кастрационных переживаний - перверсии, о чем Р.Дж. Столлер пишет в своей работе. Мальчик с недоверием реагирует впервые увидев гениталии девочки и отклоняет то (отказывается принять), что видит [11]. Это наблюдение становится более важным в связи с его страхом перед кастрацией и вызывает сильную эмоциональную реакцию, заставляя мальчика поверить в то, над чем он до сих пор смеялся. Затем он либо испытывает ужас от изуродованного существа, либо триумфально презирает девочку.

3. Фрейд в сотрудничестве с Р.М.Брюнсвик признали сложности, связанные с двойной ориентацией Эдипова комплекса [10]. Кроме чувства зависти и ненависти к отцу, мальчик также хочет занять место своей матери как объект любви своего отца. Он переживает скорбь по поводу потери бессознательно-любимого мужчины и ненависти к женщине как к сопернику. Авторы указывают, что мы не знаем точно, что предшествует Эдипову комплекс у мальчиков, но этот период включает в себя идентификацию нежной привязанности с отцом, свободной от соперничества за мать.

Фрейд далее заявил, что мальчик может фантазировать, что у него есть собственный ребенок, основанный на его все еще активном анальном эротизме, не обязательно имея феминные наклонности. Мальчики не воспринимают мать как лишенную пениса, пока не узнают, что только женщины могут рожать детей. Затем они строят сложную теорию - обмена пениса на ребенка. 


\section{Психология и психотехника 11(98) • 2016}

Несмотря на то, что Фрейд описывал фантазии о беременности у мужчин и указывал на необходимость переосмысления предэдипальной фазы у мужчины, он не упоминал о женской зависти. Это могло быть связано с его концепцией, согласно которой сексуальность у девочек развивается так же как у мальчика, и что вагинальные ощущения отсутствуют у девочек до половой зрелости ${ }^{2}$. Тайсон Р. Тайсон Ф. [5] отметят, что это спорный вопрос о вагинальном осознавании девочки и восприятие ощущений гениталий в образе собственного тела. И продолжат, женские гениталии имеют доступные для прикосновения части: половые губы, части между ними. Девочке не сложно локализовать их, трогать, обследовать. Представление об этих внешних частях гениталий может быть ранним предвестником концептуализации вагины как «открытого потенциального внутреннего пространств». Далее следует, осознание вагины, что предполагает осознавание существования пространства. То есть здесь отмечается связь гениталий с пространством внутри = представление своей вагины. И заключат, переживания тела с самого начала будет включать чувство осознания гениталий. Осознание может быть расплывчатым. Раннее осознание фрагментарное. Но с примитивным ощущением себя женщиной.

В подходе К. Абрахама об оральном и анальном происхождении зависти добавилась еще одна идея к первоначальной убежденности Фрейда в том, что ревность (а именно зависть к пенису у женщины) имеет самые ранние побуждения в Эдиповом комплексе [1; 18]. В сочетании с враждебностью зависть оказывает воздействие на оральную и анально- садистическую стадии развития и связана с импульсом ограбить другого, забрать у него то, чем тот обладает. Это идея была хорошо разработана М. Кляйн [2], которая проложила путь от зависти к пенису до зависти к кормящей груди. Зависть к груди, наполненной молоком, разрушает способность к творчеству и способность любить ${ }^{3}$.

\footnotetext{
${ }^{2}$ В настоящее время мы знаем, что вагинальные ощущения включены в образ тела девочки (женщины) задолго до наступления пубертата и даже открытия влагалища.

${ }^{3}$ Из анализа случая: зависть к груди может быть символически представлена в зависти к любого рода творению в социальном мире другого человека. «Я завидую тем, кто что-то может делать, с удовольствием, например, читать книги, писать творческие работы», где продукт творчества, в контексте нашей темы, символически переживается как сотворение ребенка. Добавим, чтение имеет бессознательное значение забирать знания из тела матери и страх ограбить ее является важным фактором торможений при чтении. Для благоприятного развития жажды знаний ребенку необходимо чувствовать, что телу матери хорошо, что оно невреди-
}

М. Кляйн считала, что фантазии о беременности и родах предшествуют фаллической стадии у маленьких девочек и мальчиков. К. Хорни объясняла страх мужчины перед женщиной в связи с угрозой потери самоуважения, а не кастрационной тревожностью и чувством половой недостаточности [7]. Джонс [Jones E.] считал заблуждением делить людей на классы - те, кто обладает пенисом и кастрированных, и указал на защитную природу фаллической фазы в развитии женщин [18].

Среди ранних авторов, занимающихся темой зависти, следует упомянуть Ф. Бема [Boehm F.] [8]. Автор приписывал желание мужчин обладать феминными характеристиками из-за своей скрытой зависти к более большому пенису ${ }^{4}$, который женщины могут себе представить. Желания смерти и кастрации по отношению к матери во время беременности не просто гнев против будущего соперника, они (желания) вызваны завистью к состоянию матери. Мальчики так же, как и девочки, воображают, что мужчина теряет свой пенис, который проникает в женщину. Она принимает и прячет его и превращает в ребенка. Изгнание ребенка из тела (акт рождения) кажется более убедительным свидетельством потенции, нежели сам процесс сотворения (оплодотворения). Наглядное видение мужчины как голова ребенка выходит из влагалища является подтверждением сказанного. Лоранд [Lorand S.] заявил, что у некоторых пациенток уменьшаются кастрационные тревоги, вызванные их желанием быть агрессивной и заменить отца, наделив его женскими гениталиями, а женщину - фаллосом [14].

Дж. Зилбуорг [Zilboorg G.] отметил, что мужская зависть к женщине более ранняя по времени развития ребенка, нежели женская зависти к мужчине. Мужчина, должно быть, безнадежно завидовал женщине-матери, которая, бесспорно, превосходила его своей способностью к деторождению.

мо. В бессознательном тело символизирует сокровищницу, хранящую все, что только можно пожелать добыть оттуда, поэтому, если оно не разрушено, не находится в сильной опасности и поэтому само не настолько опасно, значительно легче осуществлять желание получить пищу для ума, как отмечала М.Кляйн.

4 Тема «большого пениса» появляется в фантазиях мальчика в период стадии фаллического нарциссизма. Мальчику важно в это время обрести нарциссически ценное видение своего мужского тела, чувство мужественности и принять мужскую роль. Обладание большим пенисом - идеальное мужское Эго (им (большим пенисом) обладает, прежде всего, отец). Это время зависти к пенису у мальчика (в отношении женщин - зависть к груди, способности иметь детей). Мальчик озабочен тем, что его гениталии могут быть повреждены (возрастает кастрационная тревога) [5]. 
Мужчина всегда будет помнить о том, что он просто тот, кто оплодотворяет женщину и защищается от понимания этого [19]. Х. Нунберг [Nunberg H.] отмечается связь фантазии о рождении у мужчин с кастрацией и смерти [16].

Мальчики в период полового созревания часто завидуют девочке ее способности к менструации. Обряды, связанные с кровопусканием в период полового созревания («менструирующий» мужчина может наблюдаться в некоторых примитивных культурах) позволяют пережить идентификацию с женской фигурой. В результате кровопускания юноши избавляются от «враждебности», как и женщины. То есть это является примером желания мужчины стать женщиной. Б. Беттельхейм интерпретировал обряды инициации следующим образом - обрезание является символической кастрацией, мотивированной завистью отца и непосредственной враждебностью по отношению к становлению сына как мужчины. Он наблюдал группу подростков-шизофреников, двух мальчиков и двух девочек. Мальчики должны были надрезать каждый месяц «в секретном месте их тела» и смешивать свою кровь с менструацией. Девочки были зачинщиками этой идеи и восторгались этим больше, чем мальчики. Другой случай Беттельхейма - психотический мальчик восьми лет с интенсивным сознательным желанием обладать вагиной. По мнению Б. Беттельхейма, мужчина завидует женщине, ее способности производить потомство; центральная цель мужских обрядов инициации состоит в том, чтобы заявить, что мужчины также могут производить на свет детей. Целью надрезов в обрядах инициации является обеспечение мужчин половым органом и способностью равняться таковым с женщинами. Желание сделать себя женщиной, чтобы разделить ее превосходящее могущество, наблюдается у некоторых мальчиков, которые живут в окружениях, где женщины доминируют, отцы отсутствуют, старшие сестры имеют большое влияние. Такие мальчики хотят мочиться подобно девочкам, избавиться от своего пениса и вообще быть как девочки. В данном случае очевидна примитивная идентификация с предэдипальной, активной фаллической и всемогущей матерью, согласно Р.М. Брюнсвик.

Боэм [Boehm] так же отмечает тему желания иметь детей как мать, обнаружил в своем пациенте-невротике мужчине желание носить женское нижнее белье, быть беременным, родить и симулировать анатомическую идентичность с женщинами - пряча пенис между ног и подделывая женские груди. Идентификация с женщинами была выражена другим мужчиной, который специально рас- кидывал свои ноги в стороны, когда пытался вступить в гомосексуальное половое сношение. Боэм выводит термины «зависть к вагине» и «зависть к родам». Он не упоминает о менструальных фантазиях и упускает факт, что его пациент-мужчина, помимо того, что был «беременным», жаловался на предменструальную головную боль.

П. Фэргеман [Faergeman Poul M.] придерживается гипотезы, что бессознательная идея менструирования у мужчин проистекает и является одной из сторон идентификации с женщиной [12]. Автор вводит понятие «феминный комплекс» ${ }^{5}$ у мужчин и рассматривает аспекты женственности, присущие мужчине. Мужчина выражает свое желание женственности всеми способами, которые есть в его распоряжении, - в сновидениях, в поведении и движениях, в способе, которым он одевается, в обмолвках речи, в чертах характера; он может даже в сознательных фантазиях испытывать сладкие мазохистические глубокие волнения от того, что им овладели.

К. Абрахам отмечал, что желание стать женщиной является обычно универсальным для всех мужчин. Непосредственное наблюдение за мальчиками показывает, что они могут завидовать женщине, как она завидует им. Джонс, обсуждая природную зависть между полами в раннем детстве, заметил: «Мужская...зависть способности женщины рожать детей является менее оцененной...»

\footnotetext{
${ }^{5} \mathrm{M}$. Кляйн выделяет фазу феминности в развитии мальчика (ранняя идентификация с матерью на орально-садистической стадии). Комплекс феминности мальчика проявляется на ранней анально-садистической стадии вследствие травмы (фрустрации оральных желаний, препятствия анальным удовольствиям). Он «отворачивается» от матери. В комплексе феминности мальчика содержится фрустрированное желание иметь особый орган. Мальчик боится наказания за разрушение материнского тела. Он боится, что его тело будет искалечено и расчленено. В данном случае мать выступает как «кастратор». Боязнь матери сочетается с боязнью отца (активный орган отца находится в ее утробе). Именно на этом органе фокусируется боязнь кастрации отцом. Таким образом, фаза феминности характеризуется тревогой, связанной с утробой и активным органом отца и эта тревога усиливает Супер-Эго мальчика. Агрессия мальчика происходит через комплекс феминности. Она сопровождается презрением к женщине - это попытка замаскировать лежащую в ней тревогу, протест мальчика против феминной роли, но она также коренится в боязни матери, у которой он хотел украсть активный орган отца, детей и женские половые органы. В развитии мальчика за фазой феминности следует борьба прегенитальной и генитальной позиции либидо. Высшая точка (3-5 лет) - мы понимаем как эдипов конфликт. Тревога, исходящая из фазы феминности, оборачивает мальчика к отцу. Достижение полной потенции и генитальной позиции зависит от благоприятного исхода фазы феминности.
} 


\section{Психология и психотехника 11(98) • 2016}

Гловер соглашается: «... бессознательное разочарование мальчика в неспособности имитировать подвиг своей матери родить ребенка является таким же глубоким, как соответствующая ревность девочки, что она не обладает мужскими органами». Определенные, на вид простые желания, исполняющиеся сновидения мальчиков раскрывают ту же самую историю. Здоровый мальчик десяти лет сказал своей матери: «Прошлой ночью я видел во сне, что я - леди, и это настолько хорошее чувство». Нужно добавить, что одним из мотивов для зависти мальчика к девочке могут быть его регрессивные потребности - быть ребенком и баловаться, поскольку он воображает себя своей сестрой [3].

Социальные нравы принуждают мальчиков подавлять их феминные стремления ${ }^{6}$. Чем больше мужчина способен признать позитивное желание создать жизнь и подчеркнуть свой вклад в нее, тем меньше ему нужно отстаивать свою силу через деструктивные домыслы. Дальнейшее изучение значимости предэдипальной фазы у мальчика привело к тому, что акцент был вновь сделан на влиянии первичной идентификации с матерью и на проблемах, связанных с чувством гнева, ревности, соперничества и беспомощности в связи с ней как шаг к маскулинности.

В работе Ван Леувен [Van Leeuwen K.] описан случай анализа молодого человека и беременного аналитика. Анализ молодого человека раскрыл много фантазий, непосредственно связанных с беременностью психоаналитика. Реакциями пациента были не только проявление его женской идентификации в переносе и его враждебность к предполагаемому сопернику, но также и зависти к беременности аналитика [18].

Ван Леувен отметит, что анализ пациента обращает внимание на роль, которую зависть к беременности, или зависть к женщине играет в формировании мужского характера и патологии. Факт беременности аналитика способствовал сосредоточению внимания на переносе на ядерных проблемах, лежащих в основе враждебности пациента к женщинам. Только когда он преодолел свои регрессивные желания, чтобы стать младенцем аналитика и его желанием заменить мужа, он начал сталкиваться с более глубоко подавленной завистью к аналитику во всех его аспектах.

Автор продолжает, семейные трудности, желания, чтобы его возлюбленные сделали аборт, фантазии об увечьях и критика бездетной женщины относятся к проявлениям зависти к беременно-

6 Наблюдаемое явление: «Ты же мужчина, ты не должен плакать, как девчонка» - говорить взрослый мальчику. сти. Часто в анализе мужчины размышляют о том, что могли бы быть лучшими поварами, матерями или домработницами, чем их жены - это все доказательства конкуренции мужчины с женщинами. Чувственность женщин, способность вынашивать детей уже давно недооцениваются как источник зависти у мужчин. Не только мужчины-гомосексуалисты, но и мужчины с гетеросексуальной ориентацией, могут испытывать глубокое желание узурпировать место женщины, основываясь на их неспособности подражать впечатляющему, казалось бы, магическому действию сотворения ребенка.

Последствия зависти к женщине не обязательно являются негативными. Зависть к беременности может также привести к повышению производительности в делах и быть дополнительным стимулом для творчества. Желание заботиться о детях важно для развития отцовских чувств. Вопрос заключается не в том, существует ли зависть к беременности у мужчины, а в том, насколько это чувство занимает ядерную позицию в психосексуальном развитии.

Вездесущность зависти и ее психологическое воздействие хорошо известны как у мужчин, так и у женщин. Зависть может быть испытана по отношению к любому полу. Возникнув в жадной орально-инкорпорированной и оральной, и анальной-садистической стадиях развития, зависть претерпевает специфические модификации на каждом этапе психосексуального развития. Обнаружение различий между полами оказывает глубокое влияние зависти, как на девочку, так и на мальчика, а также на другие важные события в жизни ребенка, включая беременность матери, рождение сиблинга, отношение к мужественности и женственности, судьбу и направления инстинктивных желаний, возникающих во время эдипальной стадии. Уязвимость, нарциссическая травма, приводящая к чувствам неполноценности, механизмы защиты, используемые против тревоги и инстинктивных желаний - это все играет важную роль. Масштаб враждебности, направленный на мать, которая не только доставляет удовольствие и удовлетворяет, но и удерживает, наказывает и фрустрирует, имеет огромное значение.

Первым объектом любви, как для мужчин, так и для женщин является женщина, мать, которая осуществляет женскую идентификацию. Женская идентификация, ненадежная привязанность к матери, идентификация с образом пассивного отца, властная фаллическая мать, идентификация с сестрой, которая либо кажется более любимой, либо более значимой. - Ввиду всего этого не удивитель- 
но, что зависть к женщине должна играть роль в формировании мужского характера и психопатологии.

Ван Леувен отметит, вызывает сожаление тот факт, что в преподавании психоанализа не уделяется больше внимания теме зависти к беременности. Мужской нарциссизм, фаллоцентрическая ориентация времен Фрейда, влияющая как на мужчин, так и на женщин-аналитиков (женщинам тоже нужно отрицать, что они чем-то завидуют мужчинам); глубокое вытеснение этого чувства; путаница, вызванная концепцией бисексуальности; уравнение мужского пола с активной позицией и женской с пассивностью - все это мешало исследованию мужской зависти к женщинам [18].

В работе Роyс [Rose G.] иллюстрируются три случая. Автор утверждает, что значение мужских фантазий о беременности включает в себя больше, чем бисексуальность. Фантазии связаны с активными, всемогущими и гермафродитическими устремлениями. Два случая иллюстрируют, что они (фантазии о беременности) могут защищать от желания смерти и страха разлуки. В третьем случае автор предполагает, что фантазии о беременности имеют отношение к творчеству [17].

В статье Милроуд [Milrod B.] изложены бессознательные фантазии о беременности двух пациентов с паническим расстройством: мужчины и женщины. В то время как у обоих было много динамических проявлений, отмеченных ранее у пациентов с паникой, в обоих случаях эти фантазии, по-видимому, занимали особое место в их бессознательной жизни, как важные динамические организаторы их панического опыта. Предположительно, для некоторых панических пациентов эти фантазии начинают организовываться из-за того, что они позволяют избежать реальных, болезненных разлук с помощью возрождения фантазий и способствовать регрессии посредством идентификации с ребенком [15].

Конечно, не все пациенты с паническим расстройством имеют бессознательные фантазии о беременности, и не все пациенты с бессознательными фантазиями о беременности страдают от панических атак. Для обоих описанных здесь пациентов эти приступы были частично переплетены с бессознательными фантазиями о беременности, которые служили одновременно и ужасающими, и успокаивающими бессознательными фантазиями воссоединения / слияния с матерью. Для мужчины фантазия о том, что он беременный, означает, что он похож на свою мать. В этом случае ему не угрожает кастрация, следовательно, не нужно ее избегать, поскольку в фантазиях он уже такой же, как мать [15].

У. Эванс [11] в своей статье представляет случай пациента демонстрировавшего значения его беременности на фаллическом уровне; внимание привлечено к специфической интенсивности его страха кастрации. Пациент переживал беременность как акт кастрации.

Пациент был свидетелем первичной сцены (первичную сцену наблюдал через зеркало). Беременность, которую он переживал в течение сессий, была сплавом беременности его жены нескольких предыдущих лет и последней беременностью его матери, которая случилась, когда ему было семь лет. Ассоциации вели от темы рождения к его агрессивным желаниям против будущих детей в его матери. Другая фантазия была о том, что он может разорваться. Это было связано с памятью о большом животе его матери и его смешанном любопытстве и агрессии.

Детская теория о родах и половых сношениях пацента: его мать обладала пенисом; ее вагина было пенисом наизнанку. В процессе рождения - «выворачивания пениса матери» актуализировались переживания кастрации матери. Бессознательно его беременность (фантазия) была попыткой самокастрации.

Отмечается близко связанной с идей рождения - идея оргазма. И то и другое были катастрофическими событиями для пациента. Роды и оргазм были приравнены к смерти и уничтожению; они представляли мазохистский экстаз, который он и желал и боялся. В анализе эти страхи были представлены его опасением относительно конца анализа, который, как пациент высказывался, был убийством, а не лечением.

Обозначается страх касания гениталий, в связи с чем, пациент избрал специфические формы удовлетворения посредством мастурбаторной активности и удовлетворения через подглядывание.

Из-за страха кастрации он отрицал мужественность и идентифицировался с матерью. Он это сделал для того, как полагал, - чтобы быть любимым, как женщина отцом. Под властью комплекса кастрации его активный Эдип оказался подавленным. Пациент пытался разрешить свой конфликт посредством фантазий. Таким образом, механизм описанный автором - идентификация с матерью, владение ребенком (основное проявление женственности) = беременность как символическая кастрация, чтобы быть любимым отцом. Наконец, беременность была кульминацией цикла событий, которые возникли в психической травме основной сцены.

Необходимо добавить еще момент, касающий- 


\section{Психология и психотехника 11(98) • 2016}

ся некоторых эффектов беременности и рождения ребенка на мужчину. Беременность аналитика, либо беременность жены может нарушать существующее психическое равновесие и реактивировать конфликты, укорененные в младенчестве мужчины. За этим следуют изменения характера (временные или фиксированные), симптомы или торможения. Изменения тесно связаны с инфантильным поведением, включая эдипальные и доэдипальные периоды и созвездие характера, предшествовавшее беременности жены, например. Характер влияния беременности на мужчину зависит от всех аспектов личности, что обеспечивают понимание структур Эго [13].

Таким образом, аналитики выделили различные аспекты в развитии мужчины, где одним из ключевых переживаний выступает зависть к беременности и фантазии о беременности. Психоаналитический опыт показал доэдипальный период возникновения чувства зависти. Мальчик хочет быть всемогущим как мать, и иметь способность к деторождению. Это выражение гермафродитического желания и бисексуальности человека. Стадия анального эротизма позволяет мальчику фантазировать о беременности, не имея феминных наклонностей. Идентификация с матерью способ- ствует тому, что мальчик обходит кастрационные переживания, сохраняет связь с матерью (то есть предупреждает разлуку). Посредством фантазий о беременности мальчик выражает желание стать ребенком; фантазия появляется в ситуации, когда необходимо проявить мужественность. Идентификация с матерью позволяет мальчику (мужчине) стать любимым для отца. Фантазии о беременности у мужчины поддерживать идентификацию с женской фигурой, возможным источником которых (фантазий) является зависть к матери, способной к деторождению. Провоцирующие внешние обстоятельства (беременность жены, аналитика) обостряют подобного рода конфликт и приводят к потере психического равновесия мужчины, регрессии. Возникающее новое психическое равновесие зависит от структуры Эго и исходного инфантильного невроза и характера. Зачастую мы рассматриваем детство, юность и климакс как точки отсчета в динамических отношениях психики. Беременность также является одним из таких решающих периодов для мужчин и для женщин. Послеродовые реакции у женщин, включая частые депрессии, необходимо переосмыслить с учетом влияния реакции мужчины на беременность и роды у женщины, как отмечал Джевис [13].

\section{Список литературы:}

1. Абрахам К., Гловер Э., Ференци Ш. Классические психоаналитические труды. М.: Когито-Центр, 2009. 223 с.

2. Кляйн М. Зависть и благодарность. Исследование бессознательных источников. М.:Б.С.К., 2000.95 с.

3. Психология менструации и менструальных расстройств: Избранная аннотированная библиография. Ижевск: ERGO, 2008. 38 c.

4. Столлер Р.Дж. Перверсия: эротическая форма ненависти. Ижевск: ERGO, 2016. 220 c.

5. Тайсон Р., Тайсон Ф. Психоаналитические теории развития. Екатеринбург: Деловая книга, 1998. 528 с.

6. Фрейд 3. Психоаналитические этюды. Минск: Попурри, 1997. 660 с.

7. Хорни К. Психология женщины. / Собрание сочинений. Т. 4. М.: Смысл, 1997. 496 с.

8. Boehm F. The Femininity Complex in Men. // Int. J. Psychoanal. 1930. Vol. 11. P. 444-469.

9. Brunswick R.M. The Accepted Lie. // Psychoanalytic Quarterly. 1943. Vol. 12. P. 458-464.

10. Brunswick R.M. The Preoedipal Phase of the Libido Development // Psychoanalytic Quarterly. 1940. Vol. 9. P. $293-319$.

11. Evans W. Simulated Pregnancy in a Male. // Psychoanal. Q. 1951. Vol. 20. P. 165-178.

12. Faergeman Poul M. Fantasies of Menstruation in Men. // The Psychoanalytic Quarterly. 1955. Vol. 24. P. 1-19.

13. Jarvis W. Some Effects of Pregnancy and Childbirth on Men. // J. Amer. Psychoanal. Assn. 1962. Vol. 10. P. 689-700.

14. Lorand S. Role of the female penis fantasy in male character formation. // Int. J. Psychoanal. 1939. Vol. 20. P. 576-576.

15. Milrod B. Unconscious Pregnancy Fantasies as an Underlying Dynamism in Panic Disorder. // J. Amer. Psychoanal. Assn. 1998. Vol. 46. P. 673-690.

16. Nunberg H. Problems of Bisexuality as Reflected in Circumcision. London: Imago, 1949.

17. Rose G. Pregenital Aspects of Pregnancy Fantasies. // Int. J. Psycho-Anal., 1961. Vol. 42. P. 544-549.

18. Van Leeuwen K. Pregnancy Envy in the Male. // Int. J. Psycho-Anal. 1966. Vol. 47. P. 319-324.

19. Zilboorg G. Masculine and feminine. // Psychiatry. 1944. Vol. 7. P. 275-296.

\section{References (transliterated):}

1. Abrakham K., Glover E., Ferentsi Sh. Klassicheskie psikhoanaliticheskie trudy. M.: Kogito-Tsentr, 2009. 223 s.

2. Klyain M. Zavist' i blagodarnost'. Issledovanie bessoznatel'nykh istochnikov. M.:B.S.K., 2000. 95 s.

3. Psikhologiya menstruatsii i menstrual'nykh rasstroistv: Izbrannaya annotirovannaya bibliografiya. Izhevsk: ERG0, 2008.38 s.

4. Stoller R.Dzh. Perversiya: eroticheskaya forma nenavisti. Izhevsk: ERGO, 2016. 220 s.

5. Taison R., Taison F. Psikhoanaliticheskie teorii razvitiya. Ekaterinburg: Delovaya kniga, 1998. $528 \mathrm{~s}$. 
6. Freid Z. Psikhoanaliticheskie etyudy. Minsk: Popurri, 1997. 660 c.

7. Khorni K. Psikhologiya zhenshchiny. / Sobranie sochinenii. T. 4. M.: Smysl, 1997. 496 c.

8. Boehm F. The Femininity Complex in Men. // Int. J. Psychoanal. 1930. Vol. 11. P. 444-469.

9. Brunswick R.M. The Accepted Lie. // Psychoanalytic Quarterly. 1943. Vol. 12. P. 458-464.

10. Brunswick R.M. The Preoedipal Phase of the Libido Development // Psychoanalytic Quarterly. 1940. Vol. 9. P. 293-319.

11. Evans W. Simulated Pregnancy in a Male. // Psychoanal. Q. 1951. Vol. 20. P. 165-178.

12. Faergeman Poul M. Fantasies of Menstruation in Men. // The Psychoanalytic Quarterly. 1955. Vol. 24. P. 1-19.

13. Jarvis W. Some Effects of Pregnancy and Childbirth on Men. // J. Amer. Psychoanal. Assn. 1962. Vol. 10. P. 689-700.

14. Lorand S. Role of the female penis fantasy in male character formation. // Int. J. Psychoanal. 1939. Vol. 20. P. 576-576.

15. Milrod B. Unconscious Pregnancy Fantasies as an Underlying Dynamism in Panic Disorder. // J. Amer. Psychoanal. Assn. 1998. Vol. 46. P. 673-690.

16. Nunberg H. Problems of Bisexuality as Reflected in Circumcision. London: Imago, 1949.

17. Rose G. Pregenital Aspects of Pregnancy Fantasies. // Int. J. Psycho-Anal., 1961. Vol. 42. P. 544-549.

18. Van Leeuwen K. Pregnancy Envy in the Male. // Int. J. Psycho-Anal. 1966. Vol. 47. P. 319-324.

19. Zilboorg G. Masculine and feminine. // Psychiatry. 1944. Vol. 7. P. 275-296. 